\title{
Bone metabolic disorder and its contributing factors in patients with chronic kidney disease; a three-year cohort study
}

\author{
Kourosh Eftekharian $^{1 \mathbb{D}}$, Hassan Eftekhar Ardebilii ${ }^{\mathbb{D}}$, Mohammad Hossein Shojamoradi $^{1^{*} \mathbb{D}}$, Sahar \\ Samimi ${ }^{1}$ \\ ${ }^{1}$ Nephrology Research Center, Tehran University of Medical Sciences, Tehran, Iran \\ ${ }^{2}$ Department of Health Education and Promotion, School of Public Health, Institute of Health Research, Tehran University of Medical \\ Sciences, Tehran, Iran
}

\section{A R T I C L E I N F O}

Article Type:

Original

\section{Article History:}

Received: 10 December 2020

Accepted: 17 February 2021

Published online: 9 March 2021

\section{Keywords:}

Bone metabolic disorder

Calcium disorders

Chronic kidney disease

Phosphate disorders

Systolic blood pressure

Survival analysis

\begin{abstract}
A B S T RA C T
Introduction: The prevalence of bone mineral disorder is best known in end-stage renal disease (ESRD) patients, but less data is available for the earlier stages.

Objectives: We aimed to compare the prevalence of bone metabolic disorder at all stages of chronic kidney disease (CKD) and assess its contribution to CKD progression and patients' outcome.

Patients and Methods: In a retrospective cohort study, CKD patients who were under treatment for three years were selected from a nephrology clinic in Tehran, Iran. Patients' demographic and laboratory data, as well as the outcome of their treatment were gathered and analyzed.

Results: In 473 patients with an average age of $61.5,60.1 \%$ were at stage III, $35.8 \%$ were at stage IV, and $4.1 \%$ were at stage $\mathrm{V}$ of CKD. There was a significant relationship between CKD stage and serum phosphate, calcium-phosphate product, and systolic blood pressure (SBP). Furthermore, the patients' outcome was significantly related to advanced stages of CKD, higher first phosphate level, diabetes mellitus in medical history, and higher stages of SBP. By multiple Cox regression analysis, after adjustment for glomerular filtration rate (GFR), the first serum phosphate level, and the calcium-phosphate product did not contribute to the undesirable outcome.

Conclusion: Although bone metabolic disorder is more frequently seen in advanced stages of chronic kidney disease, these changes can be seen even in earlier stages of the disease. The influence of phosphate abnormality in the patients' outcome should be studied more in earlier stages for better control.
\end{abstract}

Implication for health policy/practice/research/medical education:

By evaluating more than 470 patients with chronic kidney disease, our study shows the importance of earlier monitoring for bone metabolic disorder in order to prevent further adverse outcomes of the disease and improve the prognosis of such a large population of patients. Our results also denote the need for more research in earlier stages of chronic kidney disease and its impact on bone metabolic disorder.

Please cite this paper as: Eftekharian K, Eftekhar Ardebili H, Shojamoradi MH, Samimi S. Bone metabolic disorder and its contributing factors in patients with chronic kidney disease; a three-year cohort study. J Renal Inj Prev. 2022; 11(1): e05. doi: 10.34172/jrip.2022.05.

\section{Introduction}

Bone metabolic disorder is one of the main complications of chronic kidney disease (CKD) and has been evaluated for its prevalence and symptoms in many studies. Based on Hill and colleagues' study, the estimated global prevalence of CKD is $11 \%$ to $13 \%$ (1). This complication is more prevalent in end-stage renal disease (ESRD) patients; therefore, more focus has been put on studying the prevalence of bone metabolic disorder in later stages of the disease. However, less is known about the disease 
prevalence, its contributing factors, and how these factors might impact the survival and patients' outcome in earlier stages of the disease.

\section{Objectives}

In the present study, the prevalence of the bone metabolic disorder in the outpatient setting, at a nephrology clinic, was investigated on admission. Our main objectives were to clarify the prevalence of bone metabolic disorder at the onset of treatment, identify affecting factors, and assess the patients' survival.

\section{Patients and Methods \\ Study design}

Our retrospective cohort study was conducted on CKD patients referred to a nephrology clinic in Tehran, Iran, from December of 2016 until 2019. Patients with CKD, defined as a reduction of glomerular filtration rate (GFR) below $60 \mathrm{~mL} / \mathrm{min}$ by CKD-EPI formula (2) for more than three months and/or small size kidneys on ultrasound study were included in the study. Another criterion for inclusion was compliance with treatment in the three-year interval in which patients' files were examined. Exclusion criteria were; proved malignancy at the start or less than six months of follow-up, patients younger than 12 years old, and patients who underwent renal replacement therapy (RRT) at the start of therapy.

Patients' data were retrieved from their files in the affiliated nephrology clinic. These data included as follows: gender (as the person identifies her or himself, etc.), date of birth, the possible cause of CKD, first serum creatinine, weight, first serum phosphate level, first serum albumin level, first serum calcium level, first fasting blood sugar (FBS), first systolic and diastolic blood pressure (DBP), and the outcome of their treatment such as leading to dialysis, kidney transplant or death in this three-year interval. Data were gathered in a coded manner, and patients' identities were safely guarded. Patients' GFR was estimated by CKD-EPI formula (2). Reference ranges for corrected calcium, phosphate, and calcium-phosphate product was obtained from the National Kidney Foundation's modified Kidney Disease Outcomes Quality Initiative (K/DOQI) classification of $\mathrm{CKD}$ and bone metabolism disorder (3). Systolic blood pressure (SBP) and DBP were classified based on the American College of Cardiology/American Heart Association Hypertension Guideline for blood pressure classification (4).

\section{Data analysis}

The data analysis was carried out using SPSS 26 sheet software. The mean and standard deviation of continuous data and the number and proportion of ordinal data were calculated. For comparison of continuous variables with a normal distribution and ordinal variables with continuous variables, $t$ test and ANOVA test were used, respectively. In order to examine the ordinal data, the chi-square test was used. Linear and binary regression models were applied for linear and binary mapping of data. For simple variable patient outcome examination, the Kaplan-Meier curve and log-rank tests were used. For examining the multiple variables, Cox-regression and chi-square tests were used. A $P$ value of less than 0.05 was considered significant.

\section{Results}

\section{Baseline characteristics}

A total number of 473 patients fitted our inclusion and exclusion criteria and were enrolled in the study. The patients' age ranged from 16 years to 95 years (mean 61.5, standard deviation 14.8). Around $57.9 \%$ of the patients were male, and $42.1 \%$ female. According to the CKD-EPI formula, $60.1 \%$ of patients were at stage III, $35.8 \%$ at stage IV, and $4.1 \%$ at stage V of CKD. Possible causes of CKD are demonstrated in Table 1 . While the etiology of CKD was unknown for most patients (40.6\%), in the remaining individuals, diabetes mellitus followed by glomerulopathy were the most common underlying causes $(39.9 \%$ and $9 \%$, respectively).

As demonstrated in Table 2, after categorizing the patients' serum calcium and phosphate levels according to KDOQI guideline reference ranges(5), most patients have normal phosphate and calcium levels. At more advanced stages, there are more frequent disorders in the levels of these electrolytes. Only three patients had higher than 55 $\mathrm{mg}^{2} / \mathrm{dL}^{2}$ products of calcium and phosphate, two of whom were at stage III CKD, and one was on stage V. No patient had a calcium-phosphate product of higher than $72 \mathrm{mg}^{2} /$ $\mathrm{dL}^{2}$.

The average amount of serum phosphate level in female and male patients was 4.42 and $3.93 \mathrm{mg} / \mathrm{dL}$, respectively, and the difference was significant (ANOVA test, $P$ value $=0.004$ ). There was no significant difference in the amounts of serum calcium level between female and male patients $(9.12$ and $9.30 \mathrm{mg} / \mathrm{dL}$ respectively, ANOVA test, $P$ value $=0.155)$. Parathyroid hormone $(\mathrm{PTH})$ level was documented for only 22 patients of the study population; thus, PTH analysis was excluded from the study.

\section{GFR and its contributing factors}

The values of the first systolic and DBP are demonstrated in Table 1. We found no significant relationship between the patient's CKD stage and the first DBP (ANOVA test, $P$ value $=0.96$ ). However, there was a significant relationship between the CKD stage and the first SBP (chi-square test, $P$ value $<0.001)$. The regression model for this relationship had an $\mathrm{R}^{2}$ number of $1 \%$, and the model showed an average increase of SBP of $5.2 \mathrm{~mm} \mathrm{Hg}$ by each level increase of CKD stage.

The level of FBS is demonstrated in Table 1; we found no significant relationship between GFR and FBS ( $t$ test, 
Table 1. Patients' demographic and basic data

\begin{tabular}{|c|c|c|c|c|}
\hline & Total number & $\begin{array}{c}\text { CKD stage III } \\
(60.3 \%)\end{array}$ & $\begin{array}{c}\text { CKD stage IV } \\
(35.8 \%)\end{array}$ & $\begin{array}{c}\text { CKD stage V } \\
(4.1 \%)\end{array}$ \\
\hline Age (y) & $61.5 \pm 14.8$ & $60.4 \pm 14.5$ & $64.2 \pm 14.9$ & $59.4 \pm 12.2$ \\
\hline \multicolumn{5}{|l|}{ Gender } \\
\hline Female & $(42.1 \%)$ & $85(30.1 \%)$ & 97 (57.7\%) & $13(68.4 \%)$ \\
\hline Male & (57.9\%) & 187 (69.9\%) & $71(42.3 \%)$ & $6(31.6 \%)$ \\
\hline \multicolumn{5}{|l|}{ Primary kidney disease: } \\
\hline Unknown & $167(40.6 \%)$ & $99(42.7 \%)$ & $54(40.3 \%)$ & $5(29.4 \%)$ \\
\hline Diabetes & $164(39.9 \%)$ & $84(36.2 \%)$ & $60(44.8 \%)$ & $9(52.9 \%)$ \\
\hline Glomerulopathy & $37(9 \%)$ & $27(11.6 \%)$ & $7(5.2 \%)$ & $1(5.9 \%)$ \\
\hline Urologic cause & $15(3.6 \%)$ & $9(3.9 \%)$ & $5(3.7 \%)$ & - \\
\hline Polycystic kidney disease & $15(3.6 \%)$ & $5(2.2 \%)$ & $5(3.7 \%)$ & $2(11.8 \%)$ \\
\hline Hypertension & $6(1.5 \%)$ & $3(1.3 \%)$ & $2(1.5 \%)$ & - \\
\hline Renovascular stenosis & $4(1 \%)$ & $3(1.3 \%)$ & $1(0.7 \%)$ & - \\
\hline Diabetes and urologic cause & $3(0.7 \%)$ & $2(0.9 \%)$ & - & - \\
\hline Systolic blood pressure (mm Hg) & $136 \pm 26.8$ & $138 \pm 26.4$ & $143 \pm 26.9$ & $147.5 \pm 31.0$ \\
\hline Diastolic blood pressure (mm Hg) & $75 \pm 13.3$ & $7.75 \pm 1.3$ & $79.1 \pm 1.4$ & $76.2 \pm 8.0$ \\
\hline Fasting blood sugar (mg/dL) & $128 \pm 68$ & $125 \pm 64$ & $132 \pm 77$ & $130 \pm 57.2$ \\
\hline Calcium (mg/dL) & $9.2 \pm 0.7$ & $9.3 \pm 0.7$ & $9.1 \pm 0.8$ & $8.9 \pm 0.6$ \\
\hline Phosphate (mg/dL) & $4.1 \pm 0.9$ & $4 \pm 0.9$ & $4.3 \pm 0.7$ & $4.9 \pm 1.6$ \\
\hline
\end{tabular}

Values expressed as mean \pm SD or number (percent).

Table 2. Serum phosphate and calcium levels according to the KDOQI reference range (5)

\begin{tabular}{llcccc}
\hline & \multirow{2}{*}{ CKD stage } & \multicolumn{3}{c}{ Percent } \\
\cline { 3 - 5 } & & Lower than the reference range & In reference range & Higher than the reference range \\
\hline \multirow{3}{*}{ Serum phosphate } & IV & 5.2 & 77.4 & 17.4 \\
& V & 1.7 & 77.1 & 21.2 & 15.4 \\
Serum calcium & III & 7.7 & 96.9 & 0 \\
& IV & 5.7 & 94.3 & 2.7 \\
\hline
\end{tabular}

CKD, chronic kidney disease.

$P$ value $=0.81$.

As shown in Figure 1, there was an inverse relationship between the phosphate level and GFR. The relationship was significant $(P$ value $=0.015)$, and the regression model had an $\mathrm{R}^{2}$ value of $17 \%$ and an intercept of 0.039 , i.e., each number decrease in GFR resulted in 0.039 increase in phosphate level. There was no significant relationship between the first calcium level and the GFR $(P$ value $=0.23)$.

Additionally, we found an inverse relationship between the calcium-phosphate product and GFR (Figure 2). The relationship was significant $(P<0.001)$, and the regression model had an $\mathrm{R}^{2}$ value of $4.3 \%$ and an intercept of 0.13 , i.e., each number decrease in GFR lead to a 0.13 increase in the calcium-phosphate product.

\section{Predictors of outcome}

We defined undesirable outcome as patient's treatment changing to dialysis, renal transplantation, or death. As shown in Figure 3, the stage of CKD had a significant impact on the patient's outcome (log-rank or Mantel-Cox test, $P$ value $<0.001$ ), and in a binary regression model, there was an odds ratio of -1.07 , i.e., each number decrease in patients GFR makes the odds of undesirable outcome 1.07 times higher.

As demonstrated in Figure 4, there was a significant relationship between hyperphosphatemia (defined as serum level more than $5.5 \mathrm{mg} / \mathrm{dL}$ ) and undesired outcome (log rank or Mantel-Cox test, $P$ value $=0.35$ )

Furthermore, there was a significant link between history of diabetes mellitus and undesired outcomes (Figure 5). The binary regression model showed an odds ratio of 1.78 , i.e., if the patient had a history of diabetes mellitus, there were 1.78 higher odds for the undesired outcome. Regarding the stage of systolic hypertension, as shown in Figure 6, there was a significant relationship between the stage of systolic hypertension and undesired outcome (log rank or Mantel-Cox test, $P$ value $=0.006$ ). 


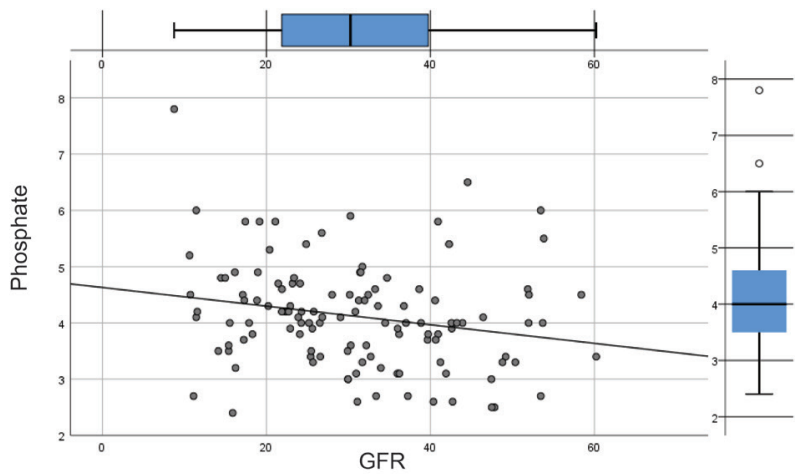

Figure 1. Patients' first phosphate level and its relationship with GFR. GFR, glomerular filtration rate.

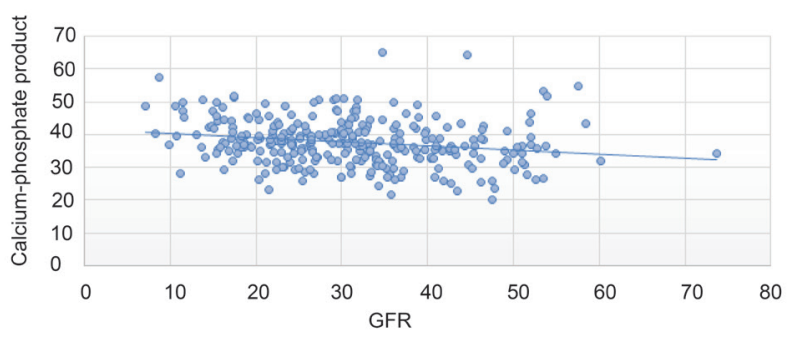

Figure 2. Calcium-phosphate products relation with GFR. GFR, glomerular filtration rate.

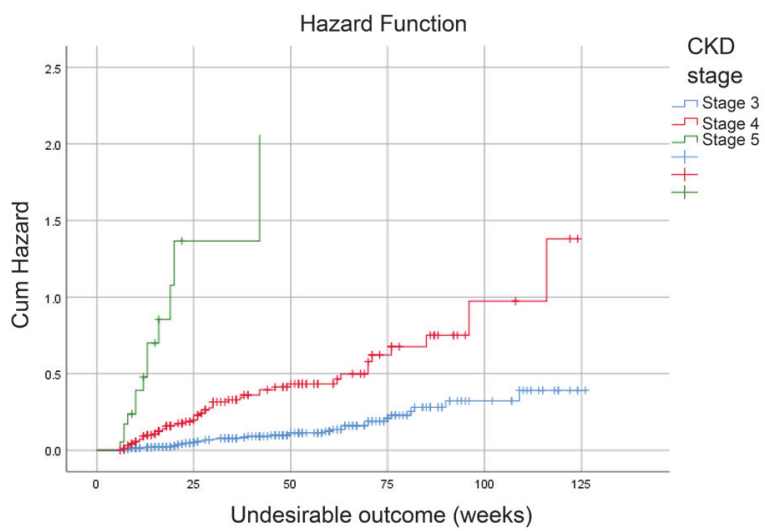

Figure 3. Undesirable outcome and CKD stage. CKD, chronic kidney disease.

By using the binary regression model, there is a 2.19 odds ratio for the undesired outcome, i.e., by each level increase in the SBP stage, the odds of undesired outcome is 2.19 higher.

As shown in Table 3 by multiple variable Cox-regression analysis, only GFR and diabetes mellitus contributed independently to the undesirable outcome. After adjustment for GFR, the first serum phosphate level and calcium-phosphate product did not contribute to the undesirable outcome.

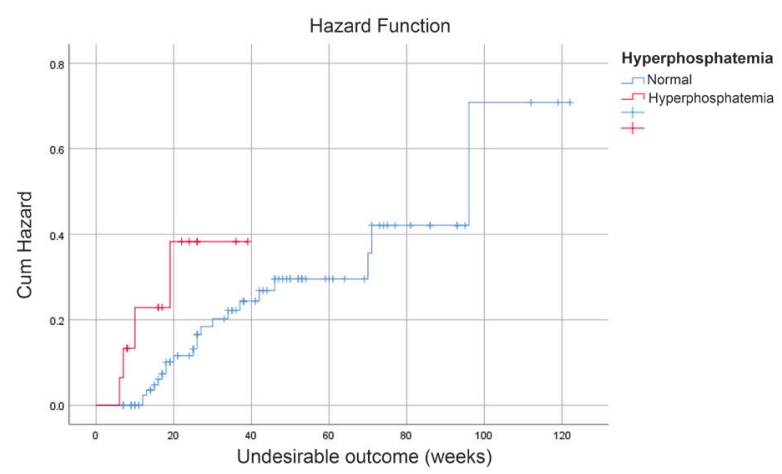

Figure 4. Undesirable outcome and hyperphosphatemia are defined as phosphate levels higher than $5.5 \mathrm{mg} / \mathrm{dL}$.

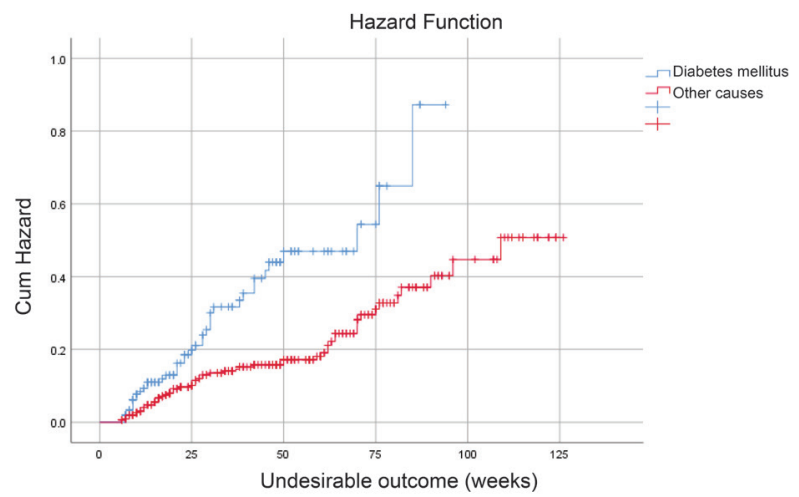

Figure 5. Undesirable outcome and diabetes mellitus as the cause of a patient's chronic kidney disease.

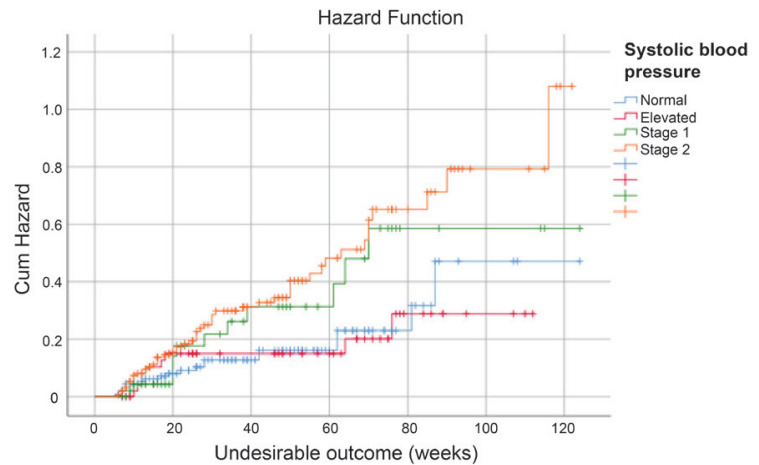

Figure 6. Undesirable outcome and patients' first systolic blood pressure (normal: below $120 \mathrm{~mm} \mathrm{Hg}$, elevated: 120-129, stage 1 hypertension: $130-139$, stage 2 hypertension: higher than 140 as defined by American heart association) (4).

\section{Discussion}

Given the high morbidity and mortality burden of CKD-related bone metabolic disorders, in this study, we demonstrate the prevalence of bone mineral abnormalities and discuss its relationship with other factors that would contribute to renal function and patients' survival. The mentioned findings were gathered from patients at earlier 
Table 3. Cox regression modeling of undesirable outcome with related contributing factors

\begin{tabular}{|c|c|c|c|c|}
\hline & GFR & Diabetes mellitus & Phosphate level & Calcium-phosphate product \\
\hline Model 1 (GFR only) & $\begin{array}{l}P \text { value }<0.001 \\
\text { Intercept }=-0.08\end{array}$ & & & \\
\hline Model 2 & $\begin{array}{l}P \text { value }<0.001 \\
\text { Intercept }=-0.08\end{array}$ & $\begin{array}{l}P \text { value }=0.001 \\
\text { Intercept }=0.69\end{array}$ & & \\
\hline Model 3 & $\begin{array}{l}P \text { value }<0.001 \\
\text { Intercept }=-0.14\end{array}$ & & $\begin{array}{l}P \text { value }=0.19 \\
\text { Intercept }=-0.35\end{array}$ & \\
\hline Model 4 & $\begin{array}{l}P \text { value }<0.001 \\
\text { Intercept }=-0.11\end{array}$ & & & $\begin{array}{l}P \text { value }=0.69 \\
\text { Intercept }=0.01\end{array}$ \\
\hline Model 5 & $\begin{array}{l}P \text { value }<0.001 \\
\text { Intercept }=-0.15\end{array}$ & $\begin{array}{l}P \text { value }=0.28 \\
\text { Intercept }=0.50\end{array}$ & $\begin{array}{l}P \text { value }=0.23 \\
\text { Intercept }=0.33\end{array}$ & \\
\hline Model 6 & $\begin{array}{l}P \text { value }<0.001 \\
\text { Intercept }=-0.15\end{array}$ & $\begin{array}{l}P \text { value }=0.023 \\
\text { Intercept }=0.62\end{array}$ & & $\begin{array}{l}P \text { value }=0.93 \\
\text { Intercept }=0.02\end{array}$ \\
\hline Model 7 & $\begin{array}{l}P \text { value }<0.001 \\
\text { Intercept }=-0.15\end{array}$ & $\begin{array}{l}P \text { value }=0.25 \\
\text { Intercept }=0.54\end{array}$ & $\begin{array}{l}P \text { value }=0.12 \\
\text { Intercept }=0.73\end{array}$ & $\begin{array}{l}P \text { value }=0.28 \\
\text { Intercept }=-0.63\end{array}$ \\
\hline
\end{tabular}

stages of CKD, in which lesser information was available from previous researches.

In the present study, the evaluation of calcium, phosphate, and calcium-phosphate product represented that the majority of patients have a normal level of these electrolytes according to KDOQI reference ranges (5). The phosphate level and calcium-phosphate product were significantly related to the function of kidneys. However, a notable association between calcium level and GFR was not observed. In this study, a significant difference in phosphate level was presented between genders; however, it is negligible due to the small contribution and is probably related to the lower initial level of glomerular filtration in the women in our study.

The results of similar cohort studies evaluating the relationship between bone mineral abnormalities with renal function and undesirable outcomes were summarized in Table 4. Comparing this research with others, the results of Levin et al (6) and Kim et al (7) are compatible with our findings, in which bone mineral parameters are in the normal range up to advanced stages of CKD (i.e., stages IV and V). Levin's and Kim's studies demonstrated a generally stable calcium and phosphate level until GFR decreased to $<20 \mathrm{~mL} / \mathrm{min} / 1.73 \mathrm{~m}^{2}$ and $<15$ $\mathrm{mL} / \mathrm{min} / 1.73 \mathrm{~m}^{2}$, respectively $(6,7)$.

Muntner et al (8), Levin et al (6), Yuste et al (9), and Patel et al (10) concur on the inverse relationship between serum phosphate level and eGFR. Our results mirror other studies, including Patel et al (10) and Muntner et al (8), in terms of calcium and renal function trends. However, Yuste et al (9) reported contradictory results by finding a significant relationship between mean serum calcium and kidney function stage.

Optimal blood pressure control has been emphasized as a vital goal to decelerate GFR reduction and reduce cardiovascular disease risk (11). Our findings were

Table 4. CKD cohorts in comparison

\begin{tabular}{|c|c|c|c|c|c|c|c|}
\hline & \multirow{2}{*}{$\begin{array}{l}\text { Sample } \\
\text { size }\end{array}$} & \multirow{2}{*}{ Age } & \multirow{2}{*}{ Follow up } & \multicolumn{2}{|c|}{ Relationship with renal function } & \multicolumn{2}{|c|}{ Relationship with the undesired outcome } \\
\hline & & & & Bone minerals & Others & Bone minerals & Others \\
\hline $\begin{array}{l}\text { Present } \\
\text { study }\end{array}$ & 473 & $\begin{array}{c}61.5 \pm \\
14.8\end{array}$ & 3 years & $\begin{array}{c}\text { Ca }(P \text { value }= \\
0.233) ; \mathrm{P}(P \text { value } \\
=0.015) ; \mathrm{Ca} * \mathrm{P}(P \\
\text { value }<0.001)\end{array}$ & $\begin{array}{l}\text { SBP }(P \text { value }<0.001) \\
\text { DBP }(P \text { value }=0.966) \\
\text { FBS }(P \text { value }=0.808)\end{array}$ & $\mathrm{P}(P$ value $=0.015)$ & $\begin{array}{c}\text { CKD stage }(P \text { value }< \\
0.001 / \mathrm{OR}=-1.07) \\
\text { Diabetes }(\mathrm{OR}=-1.07) \\
\text { SBP }(P \text { value }=0.006 / \\
\text { OR }=2.19)\end{array}$ \\
\hline $\begin{array}{l}\text { Levin et al } \\
\text { (14) }\end{array}$ & 4231 & & 31 months & - & - & $\mathrm{P}(P$ value $<0.001)$ & $\begin{array}{c}\text { GFR }(P \text { value }<0.001) \\
\text { Diabetes }(P \text { value }=0.3) \\
\text { SBP }(P \text { value }=0.04) \\
\text { DBP }(P \text { value }=0.01)\end{array}$ \\
\hline $\begin{array}{l}\text { Liu et al } \\
(17)\end{array}$ & 1126 & $\begin{array}{c}60.0 \pm \\
12.4\end{array}$ & $\begin{array}{c}3.38 \pm 1.08 \\
\text { years }\end{array}$ & - & - & $\begin{array}{c}\mathrm{Ca}(P \text { value }<0.02 / \mathrm{OR}=2.41) \\
\mathrm{P}(P \text { value }<0.01 / \mathrm{OR}=1.76)\end{array}$ & - \\
\hline $\begin{array}{l}\text { Yuste et } \\
\text { al (9) }\end{array}$ & 300 & $\begin{array}{c}65.6 \\
\pm 14.0\end{array}$ & $\begin{array}{c}19.4 \pm 10.1 \\
\text { months }\end{array}$ & $\begin{array}{c}\text { Ca }(P \text { value }< \\
0.001) ; \mathrm{P}(P \text { value }< \\
0.001)\end{array}$ & $\begin{array}{c}\text { HTN }(P \text { value }=0.02) \\
\text { Diabetes }(P \text { value }= \\
0.32)\end{array}$ & - & - \\
\hline
\end{tabular}

Data are presented as mean $\pm \mathrm{SD}$.

Note: Ca, calcium; P, phosphate; HTN, hypertension; CKD, chronic kidney disease; SBP, systolic blood pressure; DBP, diastolic blood pressure; FBS, fasting blood sugar; GFR, glomerular filtration rate. 
congruent with previous studies in terms of the relationship between blood pressure and CKD progression. We determined that the SBP significantly increased concurrently with renal function deterioration while no such link was observed regarding the DBP. The results of Lee et al (12) and Unni et al (11) both were consistent with ours, showing a directly increasing SBP with GFR and no significant relationship with DBP. Agarwal et al also concluded that SBP was a stronger predictor of ESRD, as opposed to DBP (13). However, Unni and colleagues (11) showed a significant inverse trend for DBP in correlation with GFR. Additionally, in our study, no substantial relationship was found between FBS and GFR.

In our study, an adverse outcome (i.e., dialysis, renal transplant, and death) was significantly related to the SBP, history of diabetes mellitus, GFR, and serum phosphate level. In regards to blood pressure, Agarwal et al (13) similarly reported an increase in mortality concurrent with elevated SBPs. However, in their study, low DBPs further increased the mortality in patients with SBPs greater than $170 \mathrm{~mm} \mathrm{Hg}$.

In addition to closely controlling patients' blood pressure and blood sugar (9,14-16), the following research has also addressed the role of controlling metabolic bone diseases in reducing the progression of CKD and mortality. Levin et al (14) and Liu et al (17) similarly emphasized the association of hyperphosphatemia with mortality.

Liu et al (17) demonstrated low mortality for patients who achieved the target range for serum calcium, which is not in agreement with our findings. Nevertheless, they also pointed out that achieving regulated phosphate and PTH simultaneously was associated with a lower risk of mortality, beyond the effect of proper control of serum calcium and PTH levels.

Although the present study provided useful data regarding bone metabolic disorder in CKD patients, it was not without limitations. Firstly, our study was nonrandomized, retrospective, and restricted to a single nephrology clinic; therefore, potential effects of various treatment centers have not been evaluated. Secondly, $1.25(\mathrm{OH})_{2}$ vitamin $\mathrm{D}$ was not gathered, and PTH was not analyzed due to insufficient data (i.e., 22 patients), preventing representative results. Finally, other related factors, such as dietary restrictions and compliance with various treatments, were not included in this study. Our study was consistent with previous researches and confirms the importance of regulating the serum level of bone minerals, especially phosphate, in reducing patient mortality. Our research presents that these variables are mostly abnormal in the advanced stages of kidney failure.

\section{Conclusion}

Our study demonstrated that the majority of patients in lower stages of CKD do not suffer from bone metabolic disorder, and there is a significant relationship between the kidney function and the level of serum phosphate and calcium-phosphate product. We observed a significantly higher SBP in more advanced stages of renal failure. Regarding the patients' outcome in a three-year followup, we represented that the undesired outcomes of need for dialysis or renal transplantation or death were related to advanced stages of CKD, higher first phosphate level, history of diabetes mellitus, and higher stages of SBP. In our study, after adjusting for GFR, phosphate and calciumphosphate product did not contribute to the undesirable outcome.

\section{Limitations of the study}

The shortcomings of our study were its non-random nature and not having a control group. In addition, we had few patients in stages II and V of CKD. We also were unable to examine PTH and 25(OH) Vitamin D levels due to lack of proper documentation in the patients' files. In this regard, we suggest further researches with a focus on PTH levels and a bigger population of more extreme stages of CKD (i.e., II and V).

\section{Acknowledgements}

We would like to appreciate Dr. Mitra Mahdavi-Mazdeh, the head of Nephrology Clinic in Tehran, for her kind support and collaboration in performing this research.

\section{Authors' contribution}

KE was the principal investigator and formal analyzer of the study. MHS contributed to the writing of the first draft, visualization, data curation, and validation. HEA participated in project administration, supervision, validation of data. SS, KE, and MHS revisited the manuscript and critically evaluated the intellectual contents. All authors participated in preparing the final draft, revised the manuscript and critically evaluated the intellectual contents. All authors have read and approved the manuscript and confirmed the accuracy or integrity of any part of the work.

\section{Conflicts of interest}

The authors declare that they have no conflict of interests.

\section{Ethical issues}

The research was conducted in accordance with the terms of the Declaration of Helsinki and its later amendments or comparable ethical standards. The institutional ethical committee at Tehran University of Medical Sciences approved the study protocols (IR.TUMS.IKHC. REC1396.4539). This study was extracted from the M.D., M.P.H. thesis of Kourosh Eftekharian at nephrology department of Imam-Khomeini Hospital Complex (Thesis \# 23588). Moreover, ethical issues (including plagiarism, data fabrication, double publication) have been completely observed by the authors. 


\section{Funding/Support}

This study was supported by Tehran University of Medical Sciences (Grant \# 23588).

\section{References}

1. Hill NR, Fatoba ST, Oke JL, Hirst JA, O'Callaghan CA, Lasserson DS, et al. Global prevalence of chronic kidney disease - a systematic review and meta-analysis. PLoS One. 2016;11:e0158765. doi: 10.1371/journal.pone.0158765.

2. van den Brand JAJG, van Boekel GAJ, Willems HL, Kiemeney LALM, den Heijer M, Wetzels JFM. Introduction of the CKD-EPI equation to estimate glomerular filtration rate in a Caucasian population. Nephrol Dial Transplant. 2011;26:3176-81. doi: 10.1093/ndt/gfr003.

3. K/DOQI clinical practice guidelines for chronic kidney disease: evaluation, classification, and stratification. Am J kidney Dis Off J Natl Kidney Found. 2002;39:S1-266.

4. Carey RM, Whelton PK. Prevention, Detection, evaluation, and management of high blood pressure in adults: synopsis of the 2017 American College of Cardiology/American Heart Association Hypertension Guideline. Ann Intern Med. 2018;168:351-8. doi: 10.7326/M17-3203.

5. National Kidney Foundation Kidney Disease Outcomes Quality Initiative [Internet]. Available from: https:// kidneyfoundation.cachefly.net/professionals/KDOQI/ guidelines_nutrition/doqi_nut.html.

6. Levin A, Bakris GL, Molitch M, Smulders M, Tian J, Williams LA, et al. Prevalence of abnormal serum vitamin D, PTH, calcium, and phosphorus in patients with chronic kidney disease: results of the study to evaluate early kidney disease. Kidney Int. 2007;71:31-8. doi: 10.1038/sj.ki.5002009

7. Kim CS, Bae EH, Ma SK, Han SH, Lee KB, Lee J, et al. Chronic kidney disease-mineral bone disorder in Korean Patients: a Report from the KoreaN Cohort Study for Outcomes in Patients With Chronic Kidney Disease (KNOW-CKD). J Korean Med Sci. 2017;32:240-8. doi: 10.3346/jkms.2017.32.2.240.

8. Muntner P, Jones TM, Hyre AD, Melamed ML, Alper A, Raggi $\mathrm{P}$, et al. Association of serum intact parathyroid hormone with lower estimated glomerular filtration rate. Clin J Am Soc Nephrol. 2009;4:186-94. doi: 10.2215/ CJN.03050608.
9. Yuste C, Barraca D, Aragoncillo-Sauco I, Vega-Martínez A, Abad S, Verdalles-Guzmán U, et al. Factors related with the progression of chronic kidney disease. Nefrologia. 2013;33:685-91. doi: 10.3265/Nefrologia.pre2013. May.11900.

10. Patel S, Barron JL, Mirzazedeh M, Gallagher H, Hyer $\mathrm{S}$, Cantor T, et al. Changes in bone mineral parameters, vitamin D metabolites, and PTH measurements with varying chronic kidney disease stages. J Bone Miner Metab. 2011;29:71-9. doi: 10.1007/s00774-010-0192-1.

11. Unni S, White K, Goodman M, Ye X, Mavros P, Bash LD, et al. Hypertension control and antihypertensive therapy in patients with chronic kidney disease. Am J Hypertens. 2015;28:814-22. doi: 10.1093/ajh/hpu215.

12. Lee $\mathrm{S}$, Oh HJ, Lee E-K, Lee O, Ha E, Kim S-J, et al. Blood Pressure Control During Chronic Kidney Disease Progression. Am J Hypertens. 2017;30:610-6. doi: 10.1093/ ajh/hpx017.

13. Agarwal R. Blood pressure components and the risk for end-stage renal disease and death in chronic kidney disease. Clin J Am Soc Nephrol. 2009;4:830-7. doi: 10.2215/ CJN.06201208

14. Levin A, Djurdjev O, Beaulieu M, Er L. Variability and risk factors for kidney disease progression and death following attainment of stage $4 \mathrm{CKD}$ in a referred cohort. Am J kidney Dis. 2008;52:661-71. doi: 10.1053/j.ajkd.2008.06.023

15. Chang AR, Lóser M, Malhotra R, Appel LJ. Blood pressure goals in patients with CKD: a review of evidence and guidelines. Clin J Am Soc Nephrol. 2019;14:161-9. doi: 10.2215/CJN.07440618

16. Navaneethan SD, Schold JD, Jolly SE, Arrigain S, Winkelmayer WC, Nally JVJ. Diabetes control and the risks of ESRD and mortality in patients with CKD. Am J kidney Dis. 2017;70:191-8. doi: 10.1053/j.ajkd.2016.11.018

17. Liu Y, Lee W-C, Cheng B-C, Li L-C, Lee C-H, Chang $\mathrm{W}-\mathrm{X}$, et al. Association between the achievement of target range CKD-MBD markers and mortality in prevalent hemodialysis patients in Taiwan by using the Kidney Disease: Improving Global Outcomes Clinical Guidelines. Husain K, editor. Biomed Res Int. 2016; 1523124. doi: $10.1155 / 2016 / 1523124$

Copyright ( $) 2022$ The Author(s); Published by Nickan Research Institute. This is an open-access article distributed under the terms of the Creative Commons Attribution License (http://creativecommons.org/licenses/by/4.0), which permits unrestricted use, distribution, and reproduction in any medium, provided the original work is properly cited. 